\title{
BLOW-UP OF SOLUTIONS TO A NONLINEAR WAVE EQUATION WITH A TIME DELAY CONDITION OF FRACTIONAL TYPE AND LOGARITHMIC NONLINEARITY
}

\author{
Aounallah Radhouane ${ }^{1}$, Benaissa Abbès ${ }^{2}$, and Zarai Abderrahmane ${ }^{3}$ \\ ${ }^{1}$ Djillali Liabès University, of Mathematics B. P 89 Sidi Bel Abbès 22000, Algeria \\ ${ }^{2}$ Djillali Liabès University \\ ${ }^{3}$ University of Larbi Tebessi, Tebessa,Algeria
}

April 27, 2020

\begin{abstract}
In the present work, we consider a nonlinear wave equation with a time delay condition of fractional type and a logarithmic source. Using the semigroup theory, we get the existence of a local weak solution. Moreover, we show that this solution blows up in finite time with negative initial-energy.
\end{abstract}

Hosted file 52981-Article Text-751375194053-1-2-20200405.pdf available at https://authorea.com/users/315220/articles/44558 blow-up-of-solutions-to-a-nonlinear-wave-equation-with-a-time-delay-condition-of-fractional-type-and-logarithmicnonlinearity 